\title{
Targeted induction of apoptosis by chimeric granzyme B fusion proteins carrying antibody and growth factor domains for cell recognition
}

\author{
B Dälken ${ }^{1}$, U Giesübel ${ }^{1}$, SK Knauer ${ }^{1}$ and WS Wels ${ }^{\star, 1}$ \\ ${ }^{1}$ Chemotherapeutisches Forschungsinstitut Georg-Speyer-Haus, Paul-Ehrlich- \\ Straße 42-44, D-60596 Frankfurt am Main, Germany \\ * Corresponding author: WS Wels, Chemotherapeutisches Forschungsinstitut, \\ Georg-Speyer-Haus, Paul-Ehrlich-Straße 42-44, D-60596 Frankfurt am Main, \\ Germany. Tel: + 49-69-63395-188; Fax: + 49-69-63395-189; \\ E-mail: wels@em.uni-frankfurt.de
}

Received 16.4.05; revised 13.7.05; accepted 04.8.05; published online 23.9.05 Edited by SJ Martin

\begin{abstract}
The serine protease granzyme B (GrB) of cytotoxic lymphocytes efficiently induces apoptosis by direct activation of caspases and cleavage of central caspase substrates. We employed human GrB as an effector function in chimeric fusion proteins that also contain the EGFR ligand TGF $\alpha$ or an ErbB2-specific single-chain antibody fragment (scFv) for selective targeting to tumor cells. GrB-TGF $\alpha$ (GrB-T) and GrBscFv(FRP5) (GrB-5) molecules expressed in the yeast Pichia pastoris were bifunctional, cleaving synthetic and natural GrB substrates, and binding specifically to cells expressing EGFR or ErbB2 target receptors. Upon cell binding the chimeric molecules were internalized into intracellular vesicles, but could be released into the cytosol by the endosomolytic reagent chloroquine. Treatment with picomolar to nanomolar concentrations of GrB-5 and GrB-T resulted in selective and rapid tumor cell killing, accompanied by clear signs of apoptosis such as chromatin condensation, membrane blebbing, formation of apoptotic bodies and activation of endogenous initiator and effector caspases.

Cell Death and Differentiation (2006) 13, 576-585.

doi:10.1038/sj.cdd.4401773; published online 23 September 2005
\end{abstract}

Keywords: granzyme B; apoptosis; ErbB2; HER2; EGF receptor

Abbreviations: CTL, cytotoxic T-lymphocyte; EGFR, epidermal growth factor receptor; GrB, granzyme B; mAb, monoclonal antibody; NK, natural killer; scFv, single-chain antibody fragment

\section{Introduction}

Cytotoxic T lymphocytes (CTLs) and natural killer (NK) cells are highly specialized effectors of the immune system, which are able to recognize and eliminate virus-infected or transformed cells. Upon contact with their targets, they secrete the contents of cytotoxic granules, which efficiently induce apoptotic cell death within minutes to a few hours. ${ }^{1,2}$ Together with the pore-forming protein perforin, the serineprotease granzyme B $(\mathrm{GrB})$ was recognized as the most potent effector molecule present in these cytotoxic granules. ${ }^{3}$ Thereby perforin is required to allow GrB access to substrate proteins inside target cells by mediating its release from intracellular vesicles, where the protease accumulates after uptake. ${ }^{4} \mathrm{GrB}$ is the only serine protease known to date that shares the substrate specificity of caspases, and cleaves its substrates after specific aspartate residues. ${ }^{5}$ Once inside the cytosol of a target cell, GrB induces apoptosis by mimicking caspase activity and activating caspase- 3 and other caspases. $^{6-10}$ In addition, GrB was found to cleave central caspase substrates, ${ }^{11}$ such as the $\mathrm{BH} 3$-only protein $\mathrm{Bid}^{12,13}$ and the inhibitor of the caspase-activated DNase (ICAD). ${ }^{14}$

Here, we have employed recombinant human GrB to selectively eliminate tumor cells that express the epidermal growth factor receptor (EGFR) or the closely related ErbB2 (HER2) receptor tyrosine kinase. EGFR and ErbB2 overexpression have been found in many tumors of epithelial origin, and have been shown to contribute to cellular transformation. ${ }^{15,16}$ These growth factor receptors are accessible from the extracellular space, making them attractive targets for monoclonal antibodies (mAbs), ${ }^{17}$ and antibodyderived reagents such as immunotoxins. ${ }^{18}$ For targeting to EGFR and ErbB2, we fused the proapoptotic protease GrB to the ErbB2-specific single-chain antibody fragment (scFv) $\mathrm{scFv}(\mathrm{FRP} 5),{ }^{19}$ or to transforming growth factor $\alpha(\mathrm{TGF} \alpha)^{20}$ as a natural EGFR ligand. In previous attempts to utilize GrB as an apoptosis-inducing effector, recombinant derivatives were expressed in Escherichia coli as inactive precursors, requiring in vitro cleavage after purification from bacterial lysates to yield enzymatically active GrB molecules. ${ }^{21-23}$ This necessity for in vitro activation might explain the more moderate cytotoxic activities described for these molecules. We have followed a different strategy expressing the chimeric GrB molecules as secreted proteins in the yeast Pichia pastoris without the need for refolding or in vitro activation. GrB-scFv(FRP5) (GrB-5) and GrB-TGF $\alpha$ (GrB-T) molecules purified from yeast culture supernatants retained enzymatic GrB activity, and in the presence of an endosomolytic reagent displayed high and selective cytotoxicity towards tumor cells expressing the respective target receptors.

\section{Results}

\section{Chimeric GrB fusion proteins are expressed in $P$. pastoris at high yields}

cDNA encoding mature human GrB (amino-acid residues 21-247) was fused via a (Gly $\left.{ }_{4} \mathrm{Ser}\right)_{4}-\mathrm{His}_{6}$ linker to sequences encoding the ErbB2-specific scFv antibody fragment scFv(FRP5), or the natural EGFR ligand TGF $\alpha$ in the yeast expression vector pPIC9 (Figure 1a). In the resulting expression plasmids pPIC9-GrB, pPIC9-GrB-5 and pPIC9-GrB-T, expression of mature GrB and GrB-scFv(FRP5) (GrB-5) and 
GrB-TGF $\alpha$ (GrB-T) fusion proteins carrying C-terminal myc and $\mathrm{His}_{6}$ tags is controlled by the methanol-inducible alcohol oxidase $A O X 1$ promoter, and the gene products are secreted into the culture supernatant via the $\alpha$-factor signal sequence from Saccharomyces cerevisiae. During secretion, this signal peptide is cleaved off, producing the $\mathrm{N}$-terminus of mature human GrB.

Recombinant GrB derivatives were purified from culture supernatants by single-step $\mathrm{Ni}^{2+}$-affinity chromatography to 80-90\% purity as judged by SDS-PAGE analysis (Figure 1b, lanes 1-3). Yields were 1-2 mg of purified proteins per liter of culture. Identity of the proteins was confirmed by immunoblot analysis with myc-tag-specific mAb 9E10 (Figure 1b, lanes 4-6). The proteins migrated with an apparent molecular mass significantly higher than calculated from the amino-acid sequences (38 versus $27 \mathrm{kDa}$ for $\mathrm{GrB}$; 40 versus $36 \mathrm{kDa}$ for GrB-T; 70 versus $58 \mathrm{kDa}$ for $\mathrm{GrB}-5$ ). This was due to glycosylation as demonstrated by treatment of the recombinant proteins with $\mathrm{N}$-glycosidase $\mathrm{F}$ (data not shown). As controls, inactive $\mathrm{GrB}_{\mathrm{S} 183 \mathrm{~A}}, \mathrm{GrB}_{\mathrm{S} 183 \mathrm{~A}}-5$ and $\mathrm{GrB}_{\mathrm{S} 183 \mathrm{~A}}-\mathrm{T}$ mutants, which contain an alanine instead of the active site serine $183,{ }^{24}$ were constructed and produced in $P$. pastoris as described above (data not shown).

\section{Recombinant GrB derivatives cleave synthetic and physiological GrB substrates}

Colorimetric assays were performed using the GrB-specific peptide substrate Ac-IETD-pNA. GrB-5 and GrB-T fusion proteins like unmodified GrB cleaved this substrate with
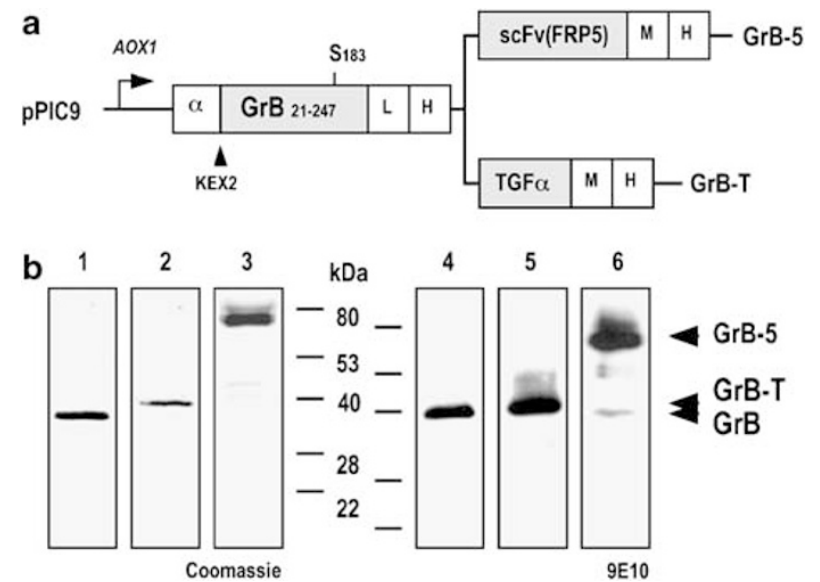

Figure 1 Expression of granzyme $\mathrm{B}$ fusion proteins in the yeast $P$. pastoris cDNA encoding mature human GrB (amino acids 21-247) was genetically fused to the $\alpha$-factor signal peptide $(\alpha)$ of $S$. cerevisiae in the expression vector pPIC9. As cell recognition domains, sequences encoding the ErbB2-specific antibody fragment scFv(FRP5) or the EGFR ligand TGF $\alpha$ were fused to the 3' end of GrB via a $\left(\mathrm{Gly}{ }_{4} \mathrm{Ser}\right)_{4}$ linker $(\mathrm{L})$ and a polyhistidine $\operatorname{tag}(\mathrm{H})(\mathbf{a})$. A myc-epitope $(\mathrm{M})$ and a second polyhistidine tag $(\mathrm{H})$ are included at the $\mathrm{C}$-termini of the gene products. During export of the GrB-scFv(FRP5) (GrB-5) and GrB-TGF $\alpha$ (GrB-T) fusion proteins, the signal peptide is removed by the $P$. pastoris protease KEX2, producing the N-terminus of mature GrB. Chimeric GrB-T (b, lanes 2, 5) and GrB-5 (b, lanes 3,6 ) proteins were purified from yeast culture supernatants by $\mathrm{Ni}^{2+}$. affinity chromatography. Eluate fractions were analyzed by SDS-PAGE and Coomassie staining (b, lanes 1-3), and immunoblotting with myc-tag-specific mAb 9E10 (b, lanes 4-6). Unmodified recombinant GrB produced in P. pastoris following a similar procedure $(\mathbf{b}$, lanes 1,4$)$ is shown for comparison comparable activity in a concentration-dependent manner (Figure 2a). High concentrations of the inactive mutants $\mathrm{GrB}_{\mathrm{S} 183 \mathrm{~A}}-5$ and $\mathrm{GrB}_{\mathrm{S} 183 \mathrm{~A}}-\mathrm{T}$ were unable to process the substrate. In addition, as a physiological GrB substrate recombinant human procaspase-3 was incubated with GrB derivatives and cleavage reactions were analyzed for production of 12 caspase-3 subunit by SDS-PAGE and immunoblotting (Figure 2b). Thereby incubation with $\mathrm{GrB}$, GrB-5 and GrB-T, but not inactive $\mathrm{GrB}_{\mathrm{S} 183 \mathrm{~A}}-5$ and $\mathrm{GrB}_{\mathrm{S183A}}-\mathrm{T}$ proteins resulted in complete processing and disappearance of procaspase-3, and detection of increased amounts of the p12 subunit.

\section{Chimeric GrB-5 and GrB-T proteins bind specifically to tumor cells}

Binding of GrB-5 and GrB-T to ErbB2 and EGFR on the surface of tumor cells was investigated by FACS analysis with human MDA-MB453 cells which express high levels of ErbB2 but no detectable EGFR, and MDA-MB468 cells which highly overexpress EGFR but have no detectable ErbB2. ${ }^{25}$ After incubation with purified fusion proteins followed by myc-tagspecific mAb 9E10 and phycoerythrin-conjugated secondary antibody, strong binding of GrB-5 to MDA-MB453 cells, and of GrB-T to MDA-MB468 cells was detected, indicating functionality of the fusion proteins' cell recognition domains (Figure 2c). Only very weak binding of the fusion proteins to the respective control cells was observed, which possibly reflects interaction of the GrB domain with structures on the cell surface ${ }^{26,27}$ (and unpublished data). Specific binding to cells expressing ErbB2 or EGFR was also found for the mutant proteins $\mathrm{GrB}_{\mathrm{S} 183 \mathrm{~A}}-5$ and $\mathrm{GrB}_{\mathrm{S}_{183 A}}-\mathrm{T}$, but not for unmodified GrB (data not shown).

Next cell killing activity of GrB-5 and GrB-T towards tumor cells expressing the respective target receptors was analyzed. To test GrB-T, MDA-MB468 and MDA-MB453 cells were used. Cytotoxic activity of GrB-5 was evaluated using murine Renca-lacZ/ErbB2 cells expressing human ErbB2 and ErbB2-negative Renca-lacZ cells as a control. ${ }^{28}$ The cells were incubated with increasing concentrations of the fusion proteins for $14 \mathrm{~h}$, before cell viability was determined in MTT assays. At concentrations up to $1 \mu \mathrm{g} / \mathrm{ml}$, the chimeric $\mathrm{GrB}$ proteins had no effect on the survival of tumor cells irrespective of the presence of their cognate target receptors on the cell surface (Figure 2d). This indicates that specific cell recognition and enzymatic activity alone are insufficient to facilitate GrB-induced cell death.

\section{GrB fusion proteins are internalized into intracellular vesicles}

We investigated internalization of the fusion proteins in human A431 epidermoid cancer cells that express both, EGFR and ErbB2 (Figure 3a). After incubation for $2.5 \mathrm{~h}$, in immunofluorescence analysis with a GrB-specific antibody the proteins were no longer detected at the cell surface, indicating efficient uptake. Instead punctuate staining within the cytoplasm was found for GrB-5 and GrB-T, suggesting localization inside vesicular structures such as endosomes. Diffuse intracellular 

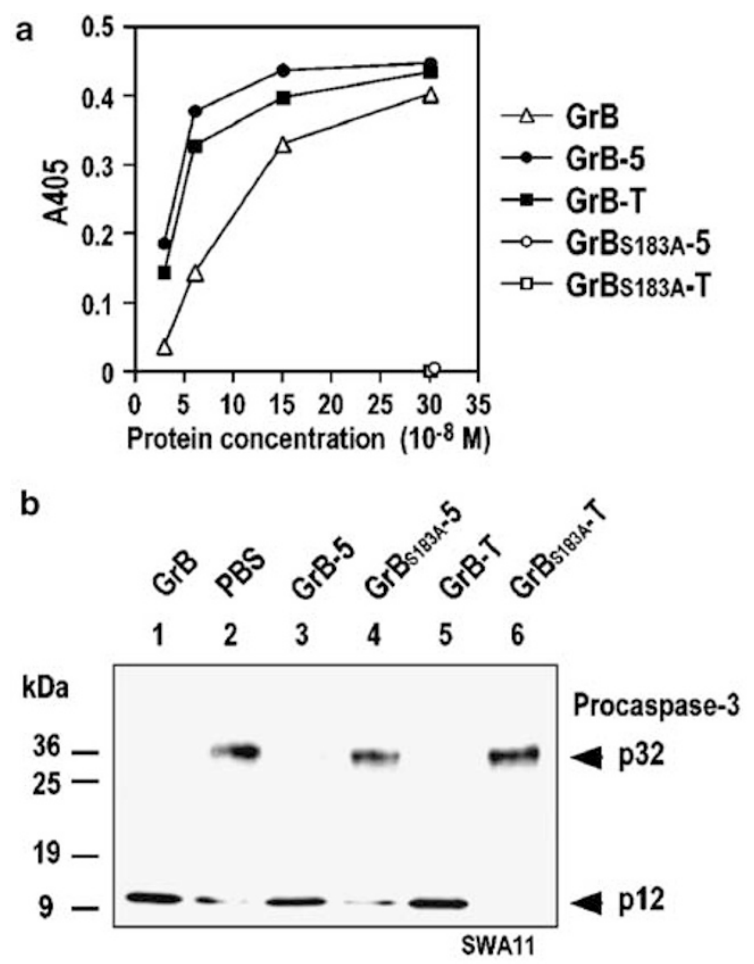

C

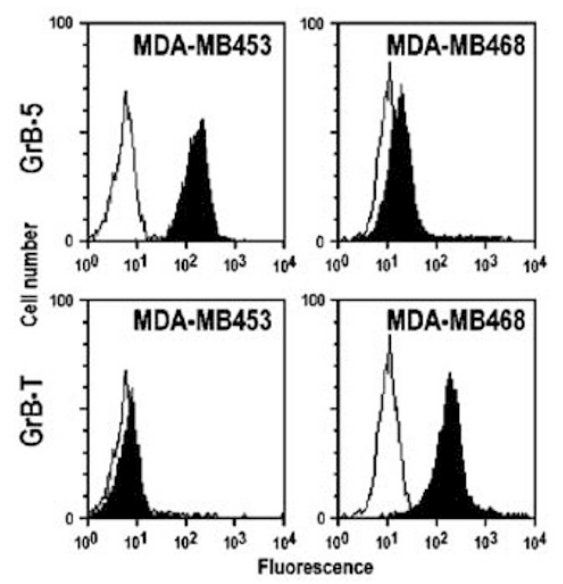

d

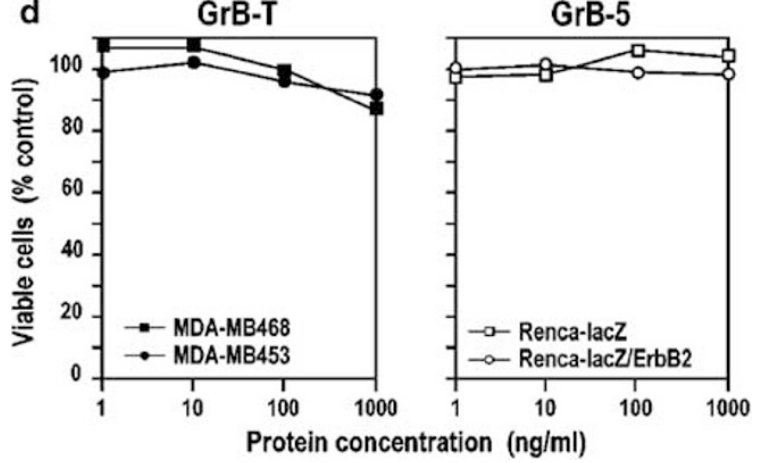

staining indicative of cytosolic localization was not observed. To investigate whether GrB fusion proteins could induce cell death if delivered directly to the cytosol, we performed microinjection experiments with GrB-5 using Renca-lacZ cells, which are ErbB2 negative and therefore unable to internalize the protein via receptor-mediated endocytosis. After $4 \mathrm{~h}$, the majority of cells that were injected with GrB-5 displayed apoptotic morphology with membrane blebbing, formation of apoptotic bodies and nuclear DNA condensation (Figure 3b). After $20 \mathrm{~h}, 68 \%$ of cells injected with GrB-5 had disintegrated into small cell fragments and could no longer be identified on the culture slides (Figure 3c). In contrast, injection of cells with the mutant protein $\mathrm{GrB}_{S 183 A}-5$ similar to injection with PBS had no effect ( $4 \%$ of apoptotic cells after $20 \mathrm{~h}$; Figure $3 \mathrm{c}$ ), confirming that induction of apoptosis was dependent on the specific activity of GrB.

\section{GrB-5 and GrB-T selectively kill tumor cells}

The basic reagent chloroquine accumulates in acidic compartments such as late endosomes and lysosomes leading to osmotic rupture of the vesicles. ${ }^{29}$ We tested whether chloroquine could release internalized GrB fusion proteins from intracellular vesicles, thereby allowing access to cytosolic GrB substrates and induction of apoptosis. As described above, EGFR expressing MDA-MB468 and ErbB2positive Renca-lacZ/ErbB2 cells were treated with increasing concentrations of GrB-T or GrB-5 in the presence of $50 \mu \mathrm{M}$ chloroquine. MDA-MB453 and Renca-lacZ cells served as controls. After $14 \mathrm{~h}$, survival of cells was determined in MTT assays (Figure 4a). In contrast to treatment in the absence of the endosomolytic reagent, incubation of the cells with GrB-T and GrB-5 in the presence of chloroquine resulted in potent and concentration-dependent cytotoxicity towards tumor cells expressing the respective target receptors $\left(\mathrm{IC}_{50}\right.$ of $10 \mathrm{ng} / \mathrm{ml}$, corresponding to $0.25 \mathrm{nM}$ for GrB-T on MDA-MB468 cells; $\mathrm{IC}_{50}$ of $20 \mathrm{ng} / \mathrm{ml}$, corresponding to $0.29 \mathrm{nM}$ for GrB-5 on RencalacZ/ErbB2 cells). MDA-MB453 control cells displayed a slight reduction in the number of viable cells at the highest GrB-T concentration of $1 \mu \mathrm{g} / \mathrm{ml}$, which might be due to the expression of small amounts of EGFR below the detection limit of EGFR

Figure 2 Chimeric GrB-T and GrB-5 fusion proteins are enzymatically active and bind to the surface of EGFR and ErbB2 overexpressing tumor cells. GrBspecific peptide substrate Ac-IETD-pNA was incubated with the indicated concentrations of purified GrB-T or GrB-5 fusion proteins for $1 \mathrm{~h}$ (a). Unmodified $\mathrm{GrB}$ and fusion proteins containing the enzymatically inactive GrB mutant $\mathrm{GrB}_{\mathrm{S183A}}$ were included as controls. Cleavage of substrate was determined by measuring the absorbance at $405 \mathrm{~nm}$. As a physiological GrB substrate, bacterially expressed procaspase-3 was incubated with the indicated concentrations of purified GrB, or GrB-5 or GrB-T fusion proteins for $14 \mathrm{~h}$ (b). Enzymatically inactive $\mathrm{GrB}_{\mathrm{S} 183 \mathrm{~A}}-5$ and $\mathrm{GrB}_{\mathrm{S183A}}-\mathrm{T}$ proteins were included as controls. Samples were analyzed by SDS-PAGE and immunoblotting. Procaspase-3 and the p12 cleavage product were detected with $\mathrm{mAb}$ SWA11 recognizing an epitope tag included at the C-terminus of recombinant procaspase-3. Specific binding of GrB5 and GrB-T proteins to the surface of tumor cells was investigated by FACS analysis using human breast carcinoma cells which express high ErbB2 (MDAMB453), or high EGFR levels (MDA-MB468) (c). Bound proteins were detected with myc-tag-specific $\mathrm{mAb} 9 \mathrm{E} 10$ followed by phycoerythrin-conjugated secondary antibody. Cytotoxic activity of GrB-T and GrB-5 fusion proteins (d). EGFR overexpressing MDA-MB468 and MDA-MB453 control cells (left panel), or murine Renca-lacZ/ErbB2 renal carcinoma cells stably transfected with human c-erbB2 cDNA and ErbB2-negative Renca-lacZ control cells (right panel) were incubated for $14 \mathrm{~h}$ with the indicated concentrations of GrB-T (left panel) or GrB-5 (right panel). Then the relative number of viable cells in comparison to PBS treated controls was determined using an MTT metabolization assay 

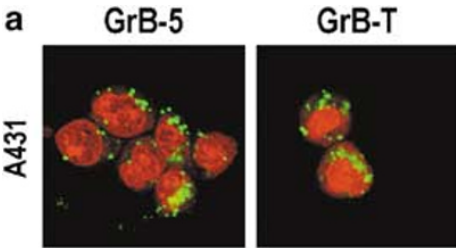

b
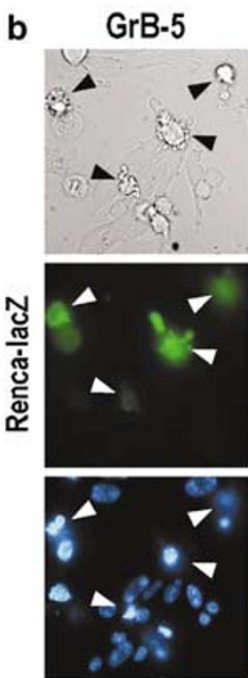

GrBs183A-5
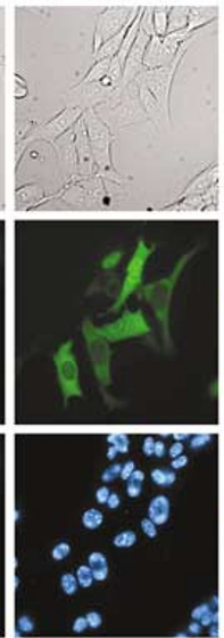

PBS

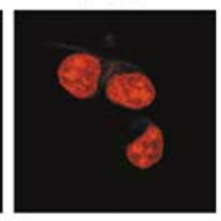

PBS

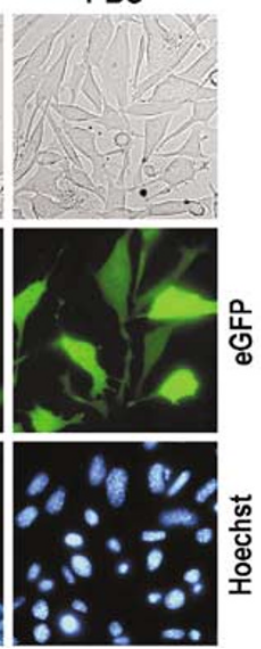

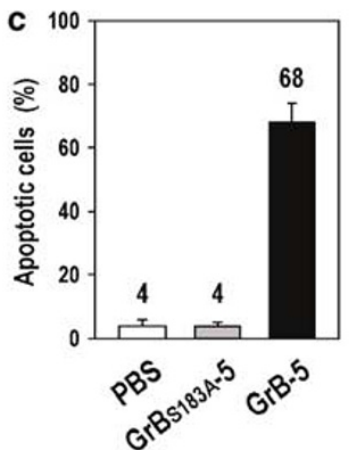

\begin{tabular}{|c|c|c|}
\hline & \multirow{2}{*}{\multicolumn{2}{|c|}{ Number of cells }} \\
\hline & & \\
\hline PBS & 294 & 286 \\
\hline GrBs183A-5 & 293 & 283 \\
\hline GrB-5 & 318 & 114 \\
\hline
\end{tabular}

Figure 3 GrB-5 and GrB-T proteins are taken up into intracellular vesicles. Human A431 epidermoid cancer cells expressing both target receptors EGFR and ErbB2, were grown on coverslips, treated with GrB-5 or GrB-T for $1 \mathrm{~h}$, washed and incubated for another $1.5 \mathrm{~h}$ at $37^{\circ} \mathrm{C}$ to allow intracellular uptake (a). Cells were fixed, consecutively incubated with anti-GrB and anti-mouse Alexa Fluor 488 antibodies, and analyzed by confocal laser scanning microscopy. Nucleic acids were stained with propidium iodide. Merged images are shown. Cytosolic delivery of GrB-5 protein induces apoptotic cellular morphology. Purified GrB-5 was microinjected into the cytosol

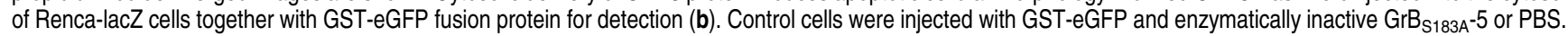
After $4 \mathrm{~h}$, injected cells were identified by fluorescence microscopy (middle panels), and cellular morphology was analyzed by phase contrast microscopy (upper panels). Nuclear morphology was analyzed by staining of cellular DNA with Hoechst 33342 dye (lower panels). Identical fields are shown. Apoptotic cells are identified by arrows. For quantification, the number of intact eGFP-containing cells was determined $20 \mathrm{~h}$ after microinjection (c). Total numbers of injected cells from three independent experiments are indicated

immunoblots. ${ }^{25}$ ErbB2-negative Renca-lacZ cells remained unaffected at the GrB-5 concentrations applied.

To confirm that even under conditions of effective endosome release cell killing activity of the GrB fusion proteins was strictly dependent on specific recognition of the ErbB2 and EGFR target receptors, Renca-lacZ/ErbB2 cells were incubated with GrB-5 and chloroquine in the presence of an excess of parental ErbB2-specific mAb FRP5, ${ }^{30}$ or a recombinant ErbB2 protein fragment encompassing the FRP5-binding epitope. ${ }^{31}$ Addition of the competitors markedly reduced GrB-5-induced cell killing (Figure 4b). Likewise, competition of binding of GrB-T to EGFR by the antagonistic EGFR-specific mAb $C 225^{17}$ resulted in a drastic reduction of its cytotoxicity towards MDA-MB468 cells. In addition to specific cell recognition, enzymatic GrB activity was required to induce cell killing (Figure $4 \mathrm{C}$ ). The mutant proteins $\mathrm{GrB}_{\mathrm{S} 183 A^{-5}}$ and $\mathrm{GrB}_{\mathrm{S} 183 \mathrm{~A}^{-}} \mathrm{T}$ were unable to kill Renca-lacZ/ ErbB2 or MDA-MD468 cells in the presence of chloroquine. Also enzymatically active GrB lacking a cell targeting domain could not induce cell death.

\section{GrB fusion proteins induce apoptotic morphology}

Cytotoxic activity of GrB-T and GrB-5 was also tested on A431 tumor cells that expresses both target receptors. In the presence of chloroquine, treatment of the cells for $14 \mathrm{~h}$ with GrB-T or GrB-5, but not unmodified GrB resulted in concentration-dependent cell killing quantified in MTT assays (Figure 5a). When cellular morphology was analyzed, A431 cells treated with GrB-T or GrB-5 displayed typical signs of apoptosis indicated by membrane blebbing and formation of apoptotic bodies (Figure $5 \mathrm{~b}$ ). In addition, chromatin condensation and fragmentation of the nuclei comparable to the effects induced by staurosporine could be detected after incubation of the cells with enzymatically active fusion proteins, but not upon treatment with $\mathrm{GrB}_{\mathrm{S} 183 \mathrm{~A}}-\mathrm{T}$ or $\mathrm{GrB}_{\mathrm{S183A}}-5$ (Figure $5 \mathrm{c}$ ). Similar results were found with $\mathrm{GrB}-\mathrm{T}$ for MDA-MB468 but not for MDA-MB453 cells, and with GrB-5 for Renca-lacZ/ErbB2 but not for Renca-lacZ cells. Signs of apoptosis could be observed as early as $2 \mathrm{~h}$ after addition of fusion proteins, which corresponds well with the kinetics described for the GrB/perforin system (data not shown).

\section{GrB-5 and GrB-T activate endogenous caspases}

We analyzed activation of endogenous caspase-3 in cytoplasmic extracts of A431 cells treated with GrB-5 or GrB-T, using the colorimetric caspase-3 peptide substrate Ac-DEVD-pNA. In addition, we investigated activation of 
a

$50 \mu \mathrm{M}$ chloroquine

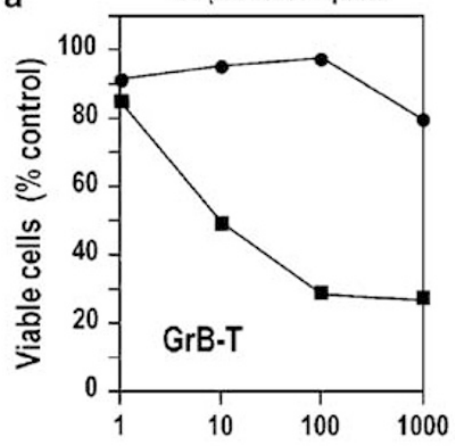

Protein concentration $(\mathrm{ng} / \mathrm{ml})$

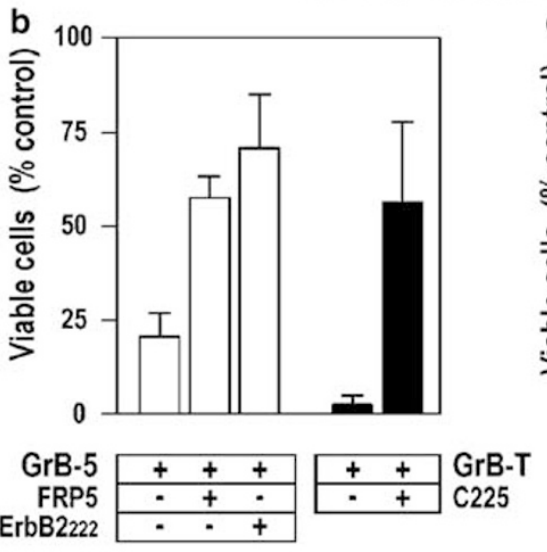

Renca-lacZ/ErbB2 MDA-MB468

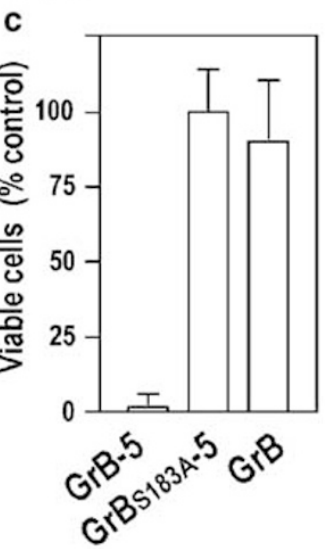

Renca-lacZ/ErbB2
50 uM chloroquine

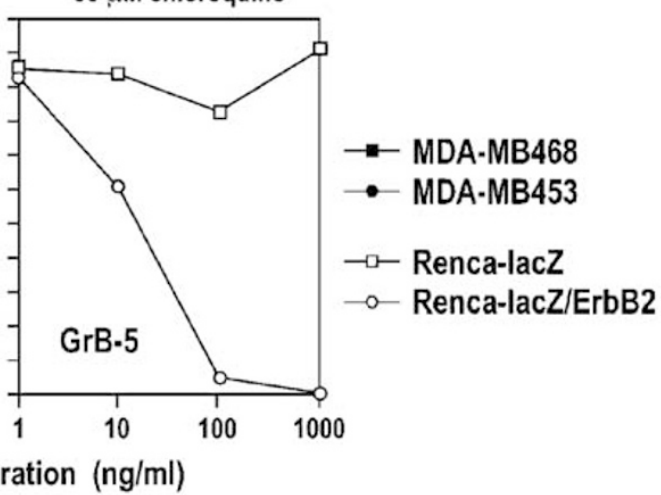

Figure 4 Addition of an endosomolytic reagent facilitates specific cell killing activity of GrB fusion proteins (a). EGFR overexpressing MDA-MB468 and MDA-MB453 control cells (left panel), or ErbB2 expressing Renca-lacZ/ErbB2 and ErbB2-negative Renca-lacZ cells (right panel) were incubated for $14 \mathrm{~h}$ with the indicated concentrations of GrB-T (left panel) or GrB-5 (right panel) in the presence of the endosomolytic reagent chloroquine. The relative number of viable cells in comparison to controls only treated with chloroquine was determined using an MTT metabolization assay. Cell killing is dependent on specific binding to target receptors and enzymatic GrB activity (b, c). Renca-lacZ/ErbB2 cells were incubated with $75 \mathrm{ng} / \mathrm{ml}$ of GrB-5 and $50 \mu \mathrm{M}$ chloroquine in the absence of competitor, or in the presence of parental ErbB2-specific mAb FRP5 or recombinant ErbB2 protein (b, open bars), or with $100 \mathrm{ng} / \mathrm{ml}$ of GrB-5, enzymatically inactive $\mathrm{GrB}_{\mathrm{s} 183 \mathrm{~A}}-5$, or an equimolar concentration of unmodified $\mathrm{GrB}$ in the presence of $50 \mu \mathrm{M}$ chloroquine (c, open bars). In the case of GrB-T, MDA-MB468 cells were treated with $100 \mathrm{ng} / \mathrm{ml}$ of the fusion protein and $50 \mu \mathrm{M}$ chloroquine in the absence or presence of the antagonistic EGFR-specific mAb C225 (b, filled bars), or with $100 \mathrm{ng} / \mathrm{ml}$ of GrB-T, enzymatically inactive GrB ${ }_{S 183 A}-\mathrm{T}$, or an equimolar concentration of unmodified GrB in the presence of $50 \mu \mathrm{M}$ chloroquine (c, filled bars). After $14 \mathrm{~h}$, the relative number of viable cells was determined in MTT assays

caspases-8 and -9 acting upstream of caspase-3, with the fluorimetric peptide substrates Ac-IETD-AFC (caspase-8) and Ac-LEHD-AFC (caspase-9). All three caspases were activated following treatment of A431 cells with GrB-5 or GrB-T in the presence of chloroquine (Figure 6a). In the absence of the endosomolytic reagent, only background activities were found. Caspase activation was dependent on both, specific cell recognition and release of GrB fusion proteins from the endosomal compartment, since independent from the presence or absence of chloroquine, GrB lacking a cell targeting domain did not induce activation of the caspases. As expected, addition of the broad-range caspase inhibitor zVAD-fmk to the cells completely blocked caspase activities.

\section{Chimeric GrB proteins cleave endogenous procaspase-3}

Processing of endogenous caspase- 3 in A431 cells treated with GrB-5 or GrB-T was analyzed by immunoblotting with a
$\mathrm{mAb}$ recognizing an epitope at the $\mathrm{N}$-terminus of caspase- 3 . In the absence of ZVAD-fmk, both p20 and p17 caspase-3 fragments were detected indicating cleavage and activation of caspase-3 (Figure 6b). In the presence of zVAD-fmk, caspase-3 p20 subunit was still produced, but p17 was absent. This is in agreement with a mechanism relying on $\mathrm{GrB}$ activity for initial cleavage of caspase-3 to generate p20, followed by autocatalytic processing to yield $p 17 .^{7}$ Only this latter step could be blocked by the caspase inhibitor ZVADfmk. Confirming the results obtained in the enzymatic assays, specific cell recognition and endosome release were required to allow GrB access to caspase-3. Treatment of the cells with unmodified $\mathrm{GrB}$, or retargeted $\mathrm{GrB}$ in the absence of chloroquine did not result in caspase-3 cleavage.

To investigate the effect of caspase inhibition on cell killing by retargeted $\mathrm{GrB}$, A431 cells were treated with GrB-5 and chloroquine in the presence or absence of ZVAD-fmk for $14 \mathrm{~h}$, before cell viability was determined in an MTT assay (Figure 6c). Importantly, while inhibition of caspases reduced 
a

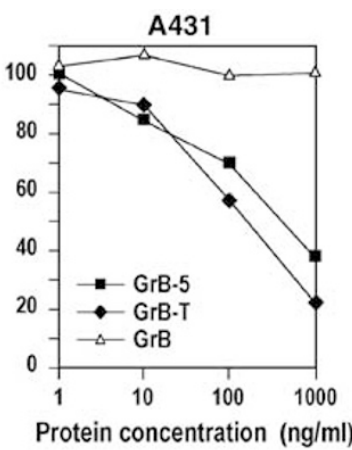

b

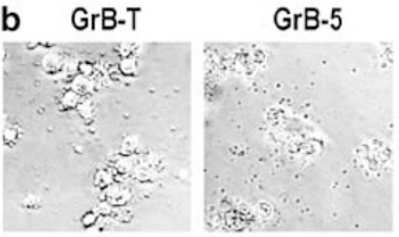

GrB

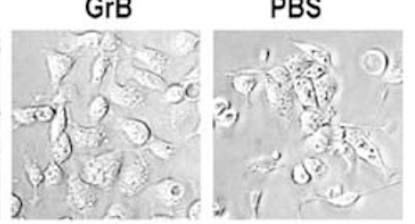

C
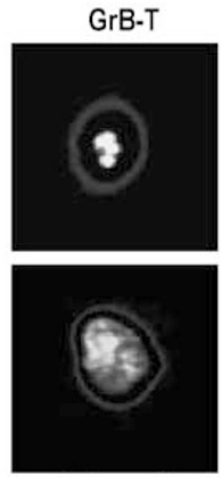

GrBs183A-T
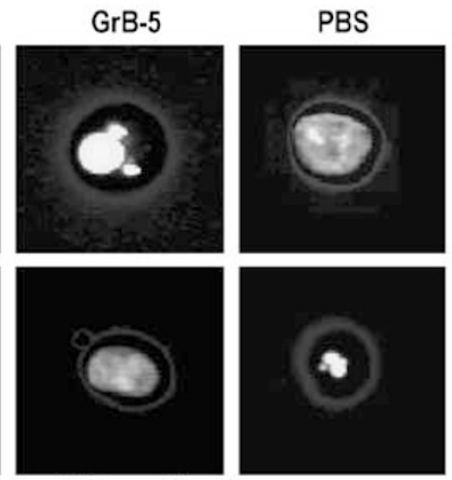

GrBs183A-5

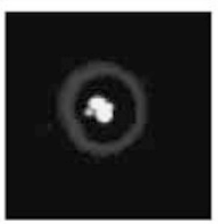

staurosporine

Figure 5 Cell killing by GrB-T and GrB-5 proteins is associated with signs of target cell apoptosis. A431 epidermoid cancer cells expressing EGFR and ErbB2 were incubated for $14 \mathrm{~h}$ with the indicated concentrations of GrB-5 or GrB-T in the presence of $100 \mu \mathrm{M}$ chloroquine. GrB lacking a targeting domain was included as a control. Then the relative number of viable cells in comparison to controls only treated with chloroquine was determined using an MTT metabolization assay (a). Morphology of A431 cells after incubation for $14 \mathrm{~h}$ with $0.5 \mu \mathrm{g} / \mathrm{ml}$ of GrB-T, $1 \mu \mathrm{g} /$ $\mathrm{ml}$ of GrB-5 or $0.5 \mu \mathrm{g} / \mathrm{ml}$ of $\mathrm{GrB}$ in the presence of $100 \mu \mathrm{M}$ chloroquine (b). Cells treated with PBS and chloroquine are shown as a control. Nuclear morphology of A431 cells was investigated after treating the cells for $14 \mathrm{~h}$ with $0.5 \mu \mathrm{g} / \mathrm{ml}$ of GrB-T or enzymatically inactive $\mathrm{GrB}_{\mathrm{S} 183 \mathrm{~A}}-\mathrm{T}$, or $1 \mu \mathrm{g} / \mathrm{ml}$ of GrB-5 or enzymatically inactive $\mathrm{GrB}_{S 183 \mathrm{~A}}-5$ in the presence of $100 \mu \mathrm{M}$ chloroquine (c). Control cells were incubated with PBS and chloroquine, or apoptosis-inducing staurosporine. Nuclei were stained with Hoechst 33342 dye before analysis of cells under a fluorescence microscope

cell killing by GrB-5, significant cytotoxic activity was still observed indicating a contribution of caspase-independent mechanisms to GrB-induced cell death.

\section{Discussion}

Recombinant antibody or growth factor toxins combine specific recognition of tumor cells with selective delivery of a potent cytotoxic effector molecule. ${ }^{18,32}$ However, due to the bacterial or plant origin of their effector domain, patients treated with such molecules can develop neutralizing antitoxin antibodies, which precludes prolonged or repeated treatment cycles that might be necessary to achieve long-lasting

therapeutic effects. Consequently, attempts are being made to reduce immunogenicity and employ cytotoxic effector functions of human origin for the construction of immunotoxin-like molecules. Here, we have derived novel chimeric proteins which carry human $\mathrm{GrB}$ as an apoptosis-inducing effector domain, and performed a detailed analysis of their in vitro activities. Specific targeting of $\mathrm{GrB}$ to tumor cells expressing high levels of the cellular proto-oncogenes EGFR or ErbB2 was achieved by fusion to the EGFR ligand TGF $\alpha$ or an ErbB2-specific scFv antibody fragment, and resulted in selective and efficient cell killing.

Different strategies have been proposed to exploit the process of cellular self-destruction for the ordered elimination of tumor cells. One approach is based on the fusion of tumorspecific cell-targeting domains to cell-death inducing cytokines such as tumor necrosis factor, CD95L or TRAIL. ${ }^{33}$ These cytokines act via death receptors on the tumor cell surface, and are therefore dependent on an intact extrinsic apoptosis pathway in the target cell. Owing to its ability to bypass common apoptosis resistance mechanisms in tumor cells, ${ }^{34}$ the serine protease $\mathrm{GrB}$ is emerging as a promising alternative effector function for immunotoxin-like molecules. $\mathrm{GrB}$ acts more downstream in the apoptosis cascade, and similar to recombinant toxins, functions via an enzymatic activity. It shares the substrate specificity of caspases and cleaves both, cellular caspases and various caspase target proteins. ${ }^{6-11}$ Like an effector caspase, GrB activates the apoptosis machinery directly and at different levels. Therefore, cell death can be induced even if one pathway is blocked. ${ }^{1,2}$ GrB has previously been employed in a fusion protein containing VEGF to target endothelial cells, ${ }^{21}$ and in chimeric proteins or immunoconjugates carrying antibody fragments for recognition of cancer cells via binding to a melanoma antigen or Lewis $Y^{22,23}$ These recombinant GrB proteins were expressed in $E$. coli as inactive precursors, requiring in vitro cleavage after purification from bacterial lysates, and in one case also refolding to yield enzymatically active molecules. In another approach, the problem to produce a functional tumor-specific GrB fusion protein was solved by coincubating tumor cells with engineered $T$ cells releasing such a molecule. ${ }^{35}$

We have followed a different strategy expressing the ErbB2-specific GrB-5 and EGFR-specific GrB-T molecules as secreted proteins in the yeast $P$. pastoris, thereby bypassing the need for refolding or in vitro activation, and resulting in large amounts of active recombinant proteins after a single purification step. Attachment of the C-terminal antibody and growth factor domains did not affect enzymatic activity of GrB. The chimeric GrB-5 and GrB-T molecules were able to cleave a synthetic GrB substrate and recombinant procaspase-3 as a natural target protein in a manner indistinguishable from unmodified $\mathrm{GrB}$. Both fusion proteins were bifunctional, in addition to enzymatic activity also displaying specific binding to cells expressing high levels of the ErbB2 or EGFR target receptors. When GrB-5 was directly injected into the cytosol of tumor cells, we observed induction of apoptosis, which was strictly dependent on enzymatic GrB activity. GrB-5 and GrB-T added from the outside, however, were unable to kill ErbB2 or EGFR expressing tumor cells unless an endosomolytic activity was present. 
a
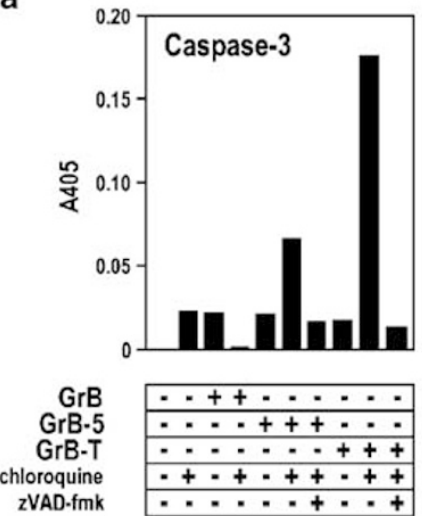
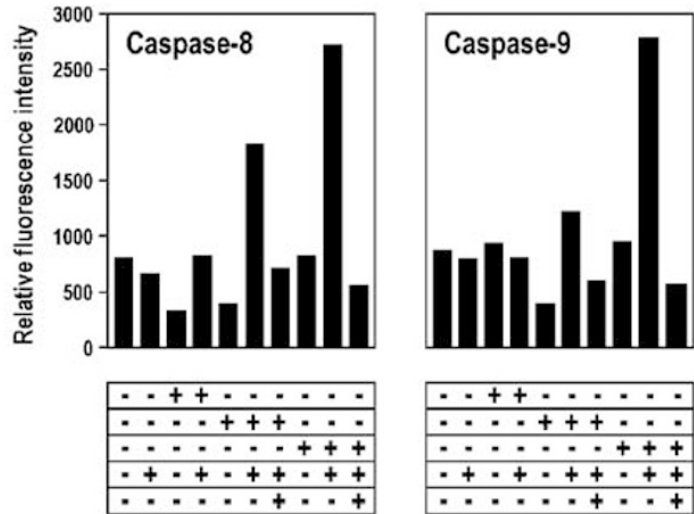
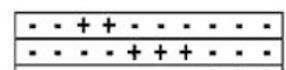

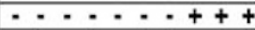

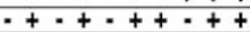

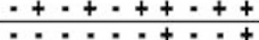
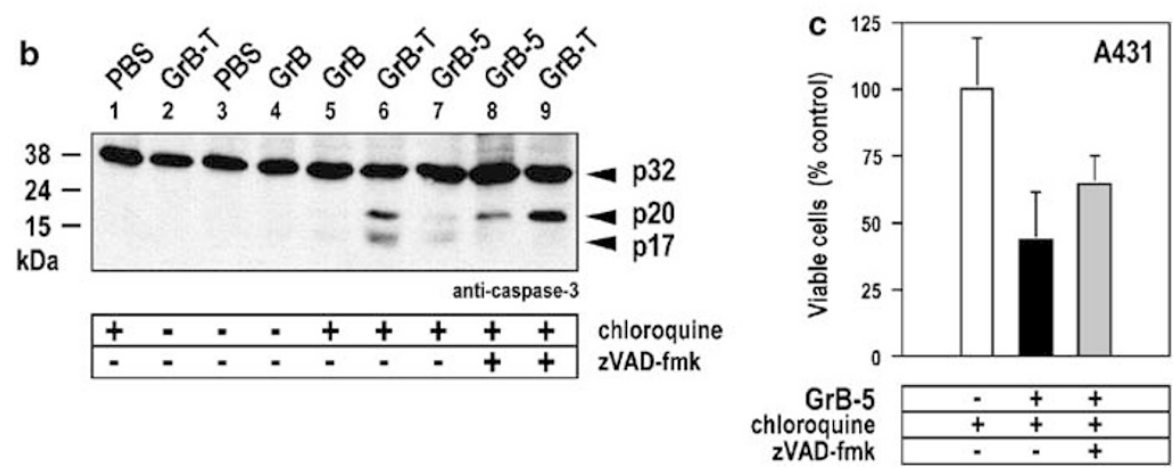

Figure 6 Treatment with GrB-5 and GrB-T results in activation of endogenous caspases. A431 cells expressing EGFR and ErbB2 target receptors were treated for $14 \mathrm{~h}$ with $1 \mu \mathrm{g} / \mathrm{ml}$ of GrB-5, $0.5 \mu \mathrm{g} / \mathrm{ml}$ of GrB-T or $0.5 \mu \mathrm{g} / \mathrm{ml}$ of GrB in the presence or absence of $100 \mu \mathrm{M}$ chloroquine and $100 \mu \mathrm{M}$ of the caspase inhibitor zVAD-fmk as indicated. Activation of endogenous caspases $-3,-8$ and -9 in response to treatment was investigated by addition of the colorimetric caspase-3 peptide substrate Ac-DEVD-pNA, or the fluorimetric peptide substrates Ac-IETD-AFC (caspase-8) or Ac-LEHD-AFC (caspase-9) to whole cell extracts (a). Cleavage of substrates was quantified by measuring the absorbance at $405 \mathrm{~nm}$ or fluorimetric analysis. To detect cleavage of caspase-3, cell extracts were analyzed by SDS-PAGE and immunoblotting with a caspase-3 specific antibody recognizing an epitope within the p17 subunit (b). To investigate the effects of caspase inhibition on GrB-5 induced cell killing, A431 cells were treated with $100 \mathrm{ng} / \mathrm{ml}$ of GrB-5 and $100 \mu \mathrm{M}$ chloroquine in the presence or absence of $100 \mu \mathrm{M} \mathrm{zVAD}$-fmk as indicated (c). After $14 \mathrm{~h}$, the relative number of viable cells was determined using an MTT assay

Wild-type GrB is able to internalize into target cells, but localizes in vesicular structures inside the cytoplasm where it remains inactive. ${ }^{4,36}$ Induction of apoptosis is only observed after the addition of perforin, which is thought to liberate GrB from these vesicles, allowing access of the protease to the cytosol. Also, GrB-5 and GrB-T were found to accumulate in intracellular vesicles without affecting cell survival. However, when the endosomolytic reagent chloroquine was present, GrB-5 and GrB-T were able to kill tumor cells at low concentrations. Importantly, this cell killing activity still required interaction with ErbB2 or EGFR target receptors and enzymatic activity of the GrB domain. Chloroquine has successfully been employed as an endosome release agent in animal models, ${ }^{37}$ and is being used as a drug for the treatment of malaria and other diseases in humans. ${ }^{38}$ Therefore, a requirement for cotreatment with chloroquine might not severely limit therapeutic applicability of GrB fusion proteins. Chloroquine accumulates in acidic compartments such as late endosomes and lysosomes, where it interferes with the $\mathrm{pH}$ equilibrium, finally leading to osmotic rupture of the vesicles. ${ }^{29}$ Therefore, retargeting of GrB to ErbB2 or EGFR must have resulted in routing to an acidic environment sensitive to chloroquine, as expected upon uptake of the fusion proteins via classical receptor-mediated endocytosis, but not typical for wild-type GrB. The membrane-disrupting potential of perforin is strongly decreased at $\mathrm{pH}$ values below $7,{ }^{39}$ making it unlikely that its role is to release GrB from late endosomes or lysosomes. Furthermore, while unmodified GrB expressed in yeast was also found in intracellular vesicles when added to cells at high concentrations (unpublished data), these vesicles did not belong to a chloroquine-sensitive, acidic compartment. The endosomolytic reagent was unable to release unmodified $\mathrm{GrB}$ into the cytosol indicated by a lack of cytotoxic activity.

Selective cytotoxic activity was also described for bacterially expressed GrB fusion proteins targeting cell surface antigens other than ErbB2 or EGFR. ${ }^{21-23}$ Thereby no endosomolytic activity was provided, suggesting different intracellular routing of chimeric GrB molecules depending on the type of target receptor. However, also in these cases addition of an endosomolytic reagent might have been beneficial, indicated by the slower kinetics of apoptosis induction and cell killing, and the requirement for 10-300 times higher protein concentrations to achieve effects similar to GrB-5 and GrB-T. ${ }^{21-23}$ The requirement for effective endosome release was also shown for a chimeric GrB protein 
which similar to GrB-5 targets ErbB2, but in an approach for adoptive cell therapy was expressed in gene modified $T$ cells. There the translocation domain of a bacterial toxin was included in the molecule to achieve cytoplasmic delivery of an active GrB fragment in target cells. ${ }^{35}$ In the presence of chloroquine, GrB-5 and GrB-T were able to specifically kill target cells with $I C_{50}$ values in the picomolar to nanomolar range, whereas nontarget cells were not affected at considerably higher concentrations. These cytotoxic activities of the chimeric GrB derivatives are comparable to those of Pseudomonas exotoxin A fusion proteins which employ the same cell targeting domains. ${ }^{20,28}$ Importantly, while such immunotoxins require incubation times of $40 \mathrm{~h}$ for maximum cell killing, high cytotoxic activity of the GrB fusion proteins was found after $14 \mathrm{~h}$ of incubation, and apoptotic morphology of target cells was observed as early as $2 \mathrm{~h}$ after addition of chimeric GrB molecules (data not shown), following kinetics similar to the $\mathrm{GrB} /$ perforin system.

A more detailed analysis of the events following treatment with GrB-5 and GrB-T was performed in A431 cells which carry both target receptors. Upon treatment of the cells with chimeric GrB proteins and chloroquine we observed hallmarks of apoptosis such as activation of initiator and effector caspases, chromatin condensation and formation of apoptotic bodies. Both, p20 and p17 caspase-3 fragments were generated, demonstrating cleavage and activation of endogenous caspase- 3 . In the presence of the broad-range caspase inhibitor zVAD-fmk only p20 subunit was produced, which is in agreement with a mechanism that relies on GrB activity for initial cleavage of caspase-3 to generate p20, followed by autocatalytic processing to yield $\mathrm{p} 17 .^{7}$ Importantly, even in the presence of the caspase inhibitor A431 cells were killed by GrB-5, albeit to a lesser extent. This ability of GrB fusion proteins to also initiate caspase-independent cell death pathways, possibly through cleavage of Bid or ICAD,$^{13,14}$ could be relevant for elimination of tumor cells with a block in caspase-dependent apoptosis.

Our data show that bifunctional, immunotoxin-like proteins employing human GrB as an effector domain can be readily expressed at high yields in the yeast $P$. pastoris. Upon specific binding to ErbB2 or EGFR on the surface of tumor cells, the chimeric molecules are internalized and can be released into the cytosol by an endosomolytic reagent, resulting in rapid and efficient cell killing. These reagents might be useful to study GrB-induced apoptosis without the requirement for perforin, but also hold promise for further development as targeted therapeutics of human origin.

\section{Materials and Methods}

\section{Construction of GrB fusion proteins}

A cDNA fragment encoding mature human $\mathrm{GrB}$ was amplified by PCR with the oligonucleotides $5^{\prime}$-GrB $5^{\prime}$-ATTCTCGAGAAAAGAATCATCGGGGG ACATGAG-3' and $3^{\prime}$-GrB $5^{\prime}$-TTTGCTAGCCCGTAGCGTTTCATGG-3' from full-length $\mathrm{GrB}$ CDNA. The PCR product was fused to a sequence encoding a myc and $\mathrm{a} \mathrm{His}{ }_{6}$ tag, and subcloned into the yeast vector pPIC9 (Invitrogen, Karlsruhe, Germany), resulting in plasmid pPIC9-GrB. Likewise, fusion genes encoding the $\mathrm{GrB}$ domain followed by a $\left(\mathrm{Gly}{ }_{4} \mathrm{Ser}\right)_{4}$ linker, an internal $\mathrm{His}_{6}$ tag, the ErbB2-specific single-chain antibody fragment $\mathrm{scFv}(\mathrm{FRP} 5),{ }^{19}$ or the EGFR ligand TGF $\alpha,{ }^{20}$ and C-terminal myc and $\mathrm{His}_{6}$ tags were assembled in pPIC9, resulting in plasmids pPIC9-GrB5 and pPIC9-GrB-T. Enzymatically inactive GrB mutants were derived from constructs encoding active enzyme by site directed mutagenesis via PCR using the oligonucleotide primers S183A-s $5^{\prime}$-CCTTTAAGGGGG ACGCTGGAGGCCCTCTTG- $3^{\prime}$ and S183A-as 5'-CAAGAGGGCCTCCA GCGTCCCCCTTAAAGG-3'.

\section{Expression and purification of recombinant proteins}

P. pastoris GS115 cells (Invitrogen) were transformed with pPIC9 plasmids via electroporation, and positive clones were selected according to the manufacturer's instructions. Single colonies were grown in $100 \mathrm{ml}$ buffered $\left(\mathrm{pH}\right.$ 8) glycerol complex medium for 2 days at $30^{\circ} \mathrm{C}$. For induction of expression, cultures were diluted 10 -fold in methanolcontaining buffered $(\mathrm{pH} 8)$ methanol complex medium to an $\mathrm{OD}_{600}$ of one, and cultured for another 4 days at $25^{\circ} \mathrm{C}$. Yeast cells were removed by centrifugation, supernatants were adjusted to $\mathrm{pH} 8$, and applied to a $\mathrm{Ni}$ NTA superflow column (Qiagen, Hilden, Germany). Specifically bound proteins were eluted with $250 \mathrm{mM}$ imidazole, $1 \mathrm{M} \mathrm{NaCl}$ in PBS, $\mathrm{pH} 8$. Protein fractions containing GrB proteins were identified by SDS-PAGE and immunoblotting with myc-tag-specific antibody 9E10, or GrB-specific mAb 2C5 (Santa Cruz Biotechnology, Heidelberg, Germany), pooled, concentrated, dialyzed against PBS and stored until use at $-80^{\circ} \mathrm{C}$.

\section{GrB activity assays}

Chimeric $\mathrm{GrB}$ molecules were incubated for $1 \mathrm{~h}$ at $37^{\circ} \mathrm{C}$ in 96-well plates with $200 \mu \mathrm{M}$ synthetic peptide substrate Ac-IETD-pNA (Alexis, Grünberg, Germany) and reaction buffer (10 mM HEPES pH 7.4, $140 \mathrm{mM} \mathrm{NaCl}$, $2.5 \mathrm{mM} \mathrm{CaCl}_{2}$ ) in a total volume of $100 \mu \mathrm{l}$ per sample. Cleavage of substrate was quantified by measuring absorbance at $405 \mathrm{~nm}$ with a microplate reader.

\section{Analysis of binding and uptake of chimeric GrB proteins}

MDA-MB468 and MDA-MB453 human breast carcinoma cells, A431 epidermoid cancer cells (ATCC), and murine Renca-lacZ and Renca-lacZ/ ErbB2 cells were cultured as described. ${ }^{20,28}$ For FACS analysis, $3 \times 10^{5}$ trypsinized cells were incubated with $1.5 \mu \mathrm{g}$ of GrB-T, GrB $\mathrm{S}_{183 \mathrm{~A}} \mathrm{~T}$, GrB-5 or $\mathrm{GrB}_{\mathrm{S}_{183 \mathrm{~A}}-5}$ for $1 \mathrm{~h}$ at $4^{\circ} \mathrm{C}$. Bound fusion proteins were detected upon subsequent incubation of the cells with $1.5 \mu \mathrm{g}$ of myc-tag-specific antibody $9 \mathrm{E} 10$ followed by $1: 50$ diluted phycoerythrin-conjugated goat anti-mouse IgG (Jackson Immuno Research, West Grove, PA, USA) in PBS at $4^{\circ} \mathrm{C}$ using a FACScan flow cytometer (Beckton Dickinson, Heidelberg, Germany). To investigate uptake of GrB-5 and GrB-T, A431 cells were grown on coverslips and treated for $1 \mathrm{~h}$ at $37^{\circ} \mathrm{C}$ with $10 \mu \mathrm{g} / \mathrm{ml}$ of the proteins in normal growth medium. Cells were washed, and incubated for another $1.5 \mathrm{~h}$ in fresh medium. Then cells were fixed with $4 \%$ paraformaldehyde in PBS for $10 \mathrm{~min}$, permeabilized in $0.1 \%$ Triton X-100 in PBS for $5 \mathrm{~min}$, and incubated with $500 \mathrm{ng} / \mathrm{ml} \mathrm{GrB}$-specific mAb 2C5 in PBS, 3\% BSA, followed by Alexa Fluor 488 donkey anti-mouse IgG (Molecular Probes, Leiden, The Netherlands) in PBS, 3\% BSA. Then samples were analyzed with a Leica TCS SL laser scanning microscope (Leica Mikrosysteme, Bensheim, Germany). Microinjection of GrB fusion proteins into the cytosol of Renca-lacZ cells was carried out following established procedures. ${ }^{40}$ 


\section{Cell viability assays}

Cells were seeded in 96-well plates at a density of 1.5 to $2 \times 10^{4}$ cells/well and incubated for $14 \mathrm{~h}$ at $37^{\circ} \mathrm{C}$ with purified $\mathrm{GrB}$ proteins in triplicate in the absence or presence of 50 or $100 \mu \mathrm{M}$ chloroquine. In some experiments, $100 \mu \mathrm{M}$ of the broad-range caspase inhibitor zVAD-fmk (Alexis) were included. The relative number of viable cells in comparison to cells grown without GrB proteins was determined in MTT assays as described. ${ }^{20}$ To compete binding to ErbB2 and EGFR, cells were preincubated for $30 \mathrm{~min}$ with ErbB2-specific mAb FRP5 ${ }^{30}$ or recombinant ErbB2 protein, ${ }^{31}$ or the antagonistic anti-EGFR antibody $\mathrm{C} 225,{ }^{17}$ before addition of chimeric $\mathrm{GrB}$ molecules and determination of cell viability.

\section{Hoechst staining}

A431 cells were seeded in 96-well plates and incubated for $14 \mathrm{~h}$ at $37^{\circ} \mathrm{C}$ with $1 \mu \mathrm{g} / \mathrm{ml}$ of GrB-5, GrB-T, or enzymatically inactive fusion proteins. As a positive control for apoptotic morphology of nuclei, cells were treated with $1 \mu \mathrm{M}$ of staurosporine. Adherent cells recovered by trypsination and detached dead cells from sample supernatants were pelleted by centrifugation, resuspended in $50 \mu \mathrm{l}$ Hoechst staining solution $(5 \mu \mathrm{g} / \mathrm{ml}$ Hoechst 33342, $1 \mu \mathrm{g} / \mathrm{ml}$ propidium iodide in PBS), incubated for $10 \mathrm{~min}$ at room temperature in the dark, and analyzed using a Nikon Eclipse TE300 fluorescence microscope.

\section{Activation of endogenous caspases}

A431 cells were incubated for $14 \mathrm{~h}$ at $37^{\circ} \mathrm{C}$ with $\mathrm{GrB}$ fusion proteins in the absence or presence of $100 \mu \mathrm{M}$ chloroquine. Control samples were in addition treated with $100 \mu \mathrm{M}$ of ZVAD-fmk. Cells were lysed in $200 \mu \mathrm{l}$ NETN buffer (20 mM Tris pH 8, $100 \mathrm{mM} \mathrm{NaCl}, 1 \mathrm{mM}$ EDTA, $0.5 \%$ NP-40, $10 \%$ glycerol, $1 \mathrm{mM}$ DTT) for $15 \mathrm{~min}$ on ice, and cell debris was removed by centrifugation. Amounts of cell extracts corresponding to $50 \mu \mathrm{g}$ of total proteins were analyzed by SDS-PAGE and immunoblotting with caspase3 specific mAb E-8 (Santa Cruz Biotechnology) followed by HRPconjugated secondary antibody and chemiluminescent detection with the ECL kit (Amersham Biosciences, Freiburg, Germany). Enzymatic activity of caspase- 3 was determined by incubating $50 \mu \mathrm{g}$ of total cellular proteins for $14 \mathrm{~h}$ at $37^{\circ} \mathrm{C}$ with $266 \mu \mathrm{M}$ of the colorimetric caspase-3 substrate Ac-DEVD-pNA (Alexis) followed by measuring the absorbance at $405 \mathrm{~nm}$. Enzymatic activity of caspases- 8 and -9 was determined by incubating $20 \mu \mathrm{g}$ of total cellular proteins for $2 \mathrm{~h}$ at $37^{\circ} \mathrm{C}$ with $37 \mu \mathrm{M}$ of the fluorimetric caspase-8 substrate Ac-IETD-AFC, or caspase-9 substrate Ac-LEHDAFC (Alexis), in a total volume of $150 \mu$ in reaction buffer $(100 \mathrm{mM}$ Tris $\mathrm{pH}$ $8,10 \%$ sucrose, $10 \mathrm{mM}$ DTT, $150 \mathrm{mM} \mathrm{NaCl}, 0.1 \% \mathrm{CHAPS}$ ). Fluorescence was measured with a Bio-Rad Fluoromark ${ }^{\mathrm{TM}}$ microplate reader (Bio-Rad, Munich, Germany).

\section{Acknowledgements}

We thank Dr. Martin Zörnig for helpful suggestions and critical reading of the manuscript.

\section{References}

1. Barry M and Bleackley RC (2002) Cytotoxic T lymphocytes: all roads lead to death. Nat. Rev. Immunol. 2: 401-409

2. Russell JH and Ley TJ (2002) Lymphocyte-mediated cytotoxicity. Annu. Rev. Immunol. 20: 323-370
3. Heusel JW, Wesselschmidt RL, Shresta S, Russell JH and Ley TJ (1994) Cytotoxic lymphocytes require granzyme $B$ for the rapid induction of DNA fragmentation and apoptosis in allogeneic target cells. Cell 76: 977-987

4. Froelich CJ, Orth K, Turbov J, Seth P, Gottlieb R, Babior B, Shah GM, Bleackley RC, Dixit VM and Hanna W (1996) New paradigm for lymphocyte granule-mediated cytotoxicity. Target cells bind and internalize granzyme B, but an endosomolytic agent is necessary for cytosolic delivery and subsequent apoptosis. J. Biol. Chem. 271: 29073-29079

5. Thornberry NA, Rano TA, Peterson EP, Rasper DM, Timkey T, Garcia-Calvo M, Houtzager VM, Nordstrom PA, Roy S, Vaillancourt JP, Chapman KT and Nicholson DW (1997) A combinatorial approach defines specificities of members of the caspase family and granzyme B. Functional relationships established for key mediators of apoptosis. J. Biol. Chem. 272: 17907-17911

6. Darmon AJ, Nicholson DW and Bleackley RC (1995) Activation of the apoptotic protease CPP32 by cytotoxic T-cell-derived granzyme B. Nature 377: 446-448

7. Martin SJ, Amarante-Mendes GP, Shi L, Chuang TH, Casiano CA, O'Brien GA, Fitzgerald P, Tan EM, Bokoch GM, Greenberg AH and Green DR (1996) The cytotoxic cell protease granzyme $B$ initiates apoptosis in a cell-free system by proteolytic processing and activation of the ICE/CED-3 family protease, CPP32, via a novel two-step mechanism. EMBO J. 15: 2407-2416

8. Medema JP, Toes RE, Scaffidi C, Zheng TS, Flavell RA, Melief CJ, Peter ME, Offringa R and Krammer PH (1997) Cleavage of FLICE (caspase-8) by granzyme B during cytotoxic T lymphocyte-induced apoptosis. Eur. J. Immunol. 27: 3492-3498

9. Yang X, Stennicke HR, Wang B, Green DR, Janicke RU, Srinivasan A, Seth P, Salvesen GS and Froelich CJ (1998) Granzyme B mimics apical caspases. Description of a unified pathway for trans-activation of executioner caspase-3 and -7. J. Biol. Chem. 273: 34278-34283

10. Adrain C, Murphy BM and Martin SJ (2005) Molecular ordering of the caspase activation cascade initiated by the cytotoxic T lymphocyte/natural killer (CTL/ NK) protease granzyme B. J. Biol. Chem. 280: 4663-4673

11. Andrade F, Roy S, Nicholson D, Thornberry N, Rosen A and Casciola-Rosen L (1998) Granzyme B directly and efficiently cleaves several downstream caspase substrates: implications for CTL-induced apoptosis. Immunity 8: $451-460$

12. Barry M, Heibein JA, Pinkoski MJ, Lee SF, Moyer RW, Green DR and Bleackley RC (2000) Granzyme B short-circuits the need for caspase 8 activity during granule-mediated cytotoxic T-lymphocyte killing by directly cleaving Bid. Mol. Cell Biol. 20: 3781-3794

13. Waterhouse NJ, Sedelies KA, Browne KA, Wowk ME, Newbold A, Sutton VR, Clarke CJ, Oliaro J, Lindemann RK, Bird PI, Johnstone RW and Trapani JA (2005) A central role for bid in Granzyme B-induced apoptosis. J. Biol. Chem. 280: 4476-4482

14. Thomas DA, Du C, Xu M, Wang X and Ley TJ (2000) DFF45/ICAD can be directly processed by granzyme $B$ during the induction of apoptosis. Immunity 12: $621-632$

15. Olayioye MA, Neve RM, Lane HA and Hynes NE (2000) The ErbB signaling network: receptor heterodimerization in development and cancer. EMBO J. 19: 3159-3167

16. Yarden $Y$ and Sliwkowski MX (2001) Untangling the ErbB signalling network. Nat. Rev. Mol. Cell Biol. 2: 127-137

17. Mendelsohn $J$ and Baselga $J(2000)$ The EGF receptor family as targets for cancer therapy. Oncogene 19: 6550-6565

18. Wels W, Biburger M, Müller T, Dälken B, Giesübel U, Tonn T and Uherek $C$ (2004) Recombinant immunotoxins and retargeted killer cells: employing engineered antibody fragments for tumor-specific targeting of cytotoxic effectors. Cancer Immunol. Immunother. 53: 217-226

19. Wels W, Harwerth IM, Mueller M, Groner B and Hynes NE (1992) Selective inhibition of tumor cell growth by a recombinant single-chain antibody-toxin specific for the erbB-2 receptor. Cancer Res. 52: 6310-6317

20. Schmidt M, Vakalopoulou E, Schneider DW and Wels W (1997) Construction and functional characterization of ScFv(14E1)-ETA - a novel, highly potent antibody-toxin specific for the EGF receptor. Br. J. Cancer 75: 1575-1584

21. Liu Y, Cheung LH, Thorpe P and Rosenblum MG (2003) Mechanistic studies of a novel human fusion toxin composed of vascular endothelial growth factor (VEGF)121 and the serine protease granzyme B: directed apoptotic events in vascular endothelial cells. Mol. Cancer Ther. 2: 949-959

22. Liu Y, Cheung LH, Hittelman WN and Rosenblum MG (2003) Targeted delivery of human pro-apoptotic enzymes to tumor cells: in vitro studies describing a 
novel class of recombinant highly cytotoxic agents. Mol. Cancer Ther. 2: $1341-1350$

23. Kurschus FC, Kleinschmidt M, Fellows E, Dornmair K, Rudolph R, Lilie $\mathrm{H}$ and Jenne DE (2004) Killing of target cells by redirected granzyme $B$ in the absence of perforin. FEBS Lett. 562: 87-92

24. Caputo A, James MN, Powers JC, Hudig D and Bleackley RC (1994) Conversion of the substrate specificity of mouse proteinase granzyme B. Nat. Struct. Biol. 1: 364-367

25. Hoffmann M, Schmidt M and Wels W (1998) Activation of EGF receptor family members suppresses the cytotoxic effects of tumor necrosis factor-alpha. Cancer Immunol. Immunother. 47: 167-175

26. Dressel R, Raja SM, Honing S, Seidler T, Froelich CJ, von Figura K and Gunther E (2004) Granzyme-mediated cytotoxicity does not involve the mannose 6phosphate receptors on target cells. J. Biol. Chem. 279: 20200-20210

27. Kurschus FC, Bruno R, Fellows E, Falk CS and Jenne DE (2005) Membrane receptors are not required to deliver granzyme $B$ during killer cell attack. Blood 105: 2049-2058

28. Maurer-Gebhard M, Schmidt M, Azemar M, Altenschmidt U, Stöcklin E, Wels W and Groner B (1998) Systemic treatment with a recombinant erbB-2 receptorspecific tumor toxin efficiently reduces pulmonary metastases in mice injected with genetically modified carcinoma cells. Cancer Res. 58: 2661-2666

29. Zenke M, Steinlein P, Wagner E, Cotten M, Beug H and Birnstiel ML (1990) Receptor-mediated endocytosis of transferrin-polycation conjugates: an efficient way to introduce DNA into hematopoietic cells. Proc. Natl. Acad. Sci. USA 87: 3655-3659

30. Harwerth IM, Wels W, Marte BM and Hynes NE (1992) Monoclonal antibodies against the extracellular domain of the erbB-2 receptor function as partial ligand agonists. J. Biol. Chem. 267: 15160-15167

31. Gerstmayer B, Altenschmidt U, Hoffmann M and Wels W (1997) Costimulation of $\mathrm{T}$ cell proliferation by a chimeric B7-2 antibody fusion protein specifically targeted to cells expressing the erbB2 proto-oncogene. J. Immunol. 158: 4584-4590

32. Kreitman RJ (2003) Recombinant toxins for the treatment of cancer. Curr. Opin. Mol. Ther. 5: 44-51

33. Wajant $\mathrm{H}$, Gerspach J and Pfizenmaier K (2005) Tumor therapeutics by design: targeting and activation of death receptors. Cytokine Growth Factor Rev. 16: $55-76$

34. Ferrarini M, Imro MA, Sciorati C, Heltai S, Protti MP, Pellicciari C, Rovere P, Manfredi AA and Rugarli C (1999) Blockade of the Fas-triggered intracellular signaling pathway in human melanomas is circumvented by cytotoxic lymphocytes. Int. J. Cancer 81: 573-579

35. Zhao J, Zhang LH, Jia LT, Zhang L, Xu YM, Wang Z, Yu CJ, Peng WD, Wen WH, Wang CJ, Chen SY and Yang AG (2004) Secreted antibody/granzyme B fusion protein stimulates selective killing of HER2-overexpressing tumor cells. J. Biol. Chem. 279: 21343-21348

36. Shi L, Mai S, Israels S, Browne K, Trapani JA and Greenberg AH (1997) Granzyme B (GraB) autonomously crosses the cell membrane and perforin initiates apoptosis and GraB nuclear localization. J. Exp. Med. 185: 855-866

37. Zhang X, Sawyer GJ, Dong X, Qiu Y, Collins L and Fabre JW (2003) The in vivo use of chloroquine to promote non-viral gene delivery to the liver via the portal vein and bile duct. J. Gene Med. 5: 209-218

38. Raynes K (1999) Bisquinoline antimalarials: their role in malaria chemotherapy. Int. J. Parasitol. 29: 367-379

39. Griffiths GM (2003) Endocytosing the death sentence. J. Cell Biol. 160: $155-156$

40. Knauer SK, Carra G and Stauber RH (2005) Nuclear export is evolutionarily conserved in CVC paired-like homeobox proteins and influences protein stability, transcriptional activation, and extracellular secretion. Mol. Cell Biol. 25: 2573-2582 